Stefan Voigt

\title{
Towards Ever More Confusion? - The Convention's Proposal for a European Constitution
}

Contribution to the Forum on "'Issues Relating to the Constitution for an Enlarged European Union"

\section{Introduction}

The Declaration of Laeken describes purpose and aims of the European Convention. According to that Declaration, the end of the Cold War constitutes a "real transformation clearly calling for a different approach from fifty years ago, when six countries first took the lead." The aim was thus nothing less than to find a new approach for an enlarged European Union. The Declaration further stresses that the Union should refrain from interfering in every little detail in the lives of its citizens. Efficiency, transparency, and democracy should be increased. In particular, the division of competence between the Union and the Member States should be (i) clarified, (ii) simplified, and (iii) adjusted. This could lead to "restoring tasks to the Member States" as well as assigning new competences to the Union. The Declaration makes explicit mention of the possibility to create a new organ that would represent the national parliaments on the European level.

This contribution discusses whether the Draft for a European Constitution as produced by the European Convention meets the aims spelled out in the Declaration of Laeken. Two issues will be dealt with particularly: (i) has the Convention proposed an allocation of competences between Member States and Union that are in line with efficiency considerations? And (ii) would an implementation of the decision rules proposed by the Convention lead to more efficient decision-making in the European Union? Our hypothesis is that the Draft Proposal falls far short of the aims spelled out in the Declaration of Laeken.

The rest of this contribution is organized as follows: section 2 deals with the functions of a Constitution, section 3 focuses on possibilities to design "optimal” constitutional rules. These constitute the benchmark for section 4, in which those constitutional rules dealing with decision-making in the European Union are discussed. Section 5 contains a number of additional issues, and section 6 concludes with possible next steps. 


\section{The Functions of a Constitution}

A constitution can be seen as the most basic written document of a polity. It contains the rules on how to make decisions on the provision of public goods, including their financing. It entails the necessity to delineate a private from a public sphere. One means of doing so is via a catalogue of basic (negative) rights that define the private sphere. A constitution further needs to define the organs that are to provide the public goods, the modi according to which they are chosen, their specific competences including the interplay of the various organs. In federal polities, constitutions also have the function to determine the competence of the various levels of government. With regard to the European Union, this means that the allocation between Union and Member State competences should be clear-cut.

Constitutions are a specific subset of institutions. Institutions have the function of enabling individuals to form expectations that have a good chance of turning out to be correct. This refers to possible actions of both private actors and representatives of the state. Predictability is a necessary condition for forming a long time horizon, for being willing to specialize, for making long-term investment etc. Predictability is thus a crucial precondition for economic growth.

Constitutions furthermore serve to make the actions of the state legitimate. The state is endowed with the monopoly to use force, the power to tax etc. A government based on force alone is not likely to survive for long; a government attributed a low level of legitimacy by its citizens will have to spend disproportionately many resources on monitoring the behavior of its citizens which will reduce the growth prospects of a polity. Efficiency, transparency, and democracy - the three items mentioned in the Declaration of Laeken - can all be interpreted to be conducive to legitimacy.

\section{How to Design Optimal Constitutional Rules}

The premise of this section is that the EU will be enlarged from its currently 15 members to some 30 members and the question is: does the Draft Constitution preview a modification of its competences and decision-rules such that individuals who are members of the enlarged Union will be better off? Answering this question presupposes that economists have at their disposition tools that enable them to find an "optimal" solution to these issues. Among the various solutions offered, we propose to draw on the notion of "interdependence costs" proposed by Buchanan and Tullock (1962). 
In their approach, they take a rational individual who is interested in her own utility as the starting point. This individual would have to decide (1) which goods should be provided by collective action and which ones by private action, (2) whether the publicly provided goods should be provided on the European level or the nation state level, and (3) what the respective majorities used in order to decide upon the provision of public goods should be? Buchanan and Tullock (1962) gave the following basic answers: (1) goods should be provided by collective action only if private action is more expensive (57f.), (2) where possible, collective action should be organized in small rather than in large units (114f.), (3) the decision-rule should lead to the minimization of interdependence costs which are defined as the sum total of external costs ("costs that the individual expects to endure as a result of the actions of others over which he has no direct control") and decision-making costs ("costs which the individual expects to incur as a result of his own participation in an organized activity", 45f.).

The enlargement of the European Union will lead to an increase in the heterogeneity of the preferences of the citizens who are part of the Union. Suppose preferences were completely homogeneous: this would mean that the external cost that any individual would have to bare because it is in the minority should be minuscule. The same holds for decision-making costs: if all are of the same opinion, getting to a collective decision should be rather cheap. The more heterogeneous the preferences become, the higher the expected external costs. This can be seen in the figure in which two levels of heterogeneity lead to two different external cost functions. A similar argument can be made for decisionmaking costs: the more heterogeneous the preferences with regard to public goods, the steeper the slope of the curve. This means that the sum of both curves the interdependence costs - increases with the degree of heterogeneity. Public goods should be provided on the level of government on which they can be provided with least costs. The larger the Union, the higher the costs of provision on the European level. This means that the chances that the provision of public goods on the level of the nation-state are less costly increase with the size of the Union. The larger the Union, the fewer the public goods which should be optimally provided by the Union itself!

\section{FIGURE AROUND HERE}

Suppose that some goods should still be provided on the European level even after enlargement, what should be the decision-rules used in order to determine their specific characteristics? In the abstract, this should be that majority rule where interdependence costs are at a minimum. Ex ante, it is unclear whether higher 
degrees of heterogeneity lead to more or less inclusive majorities which means that the minimum of the interdependence costs can move to the right as well as to the left.

\section{The Decision-Rules of the Proposed Constitution - and their Likely Consequences}

We have just seen that the number of public goods optimally provided on the European level should decrease with the number of members; although the Declaration of Laeken explicitly mentioned the possibilities to reallocate certain tasks on the level of the Member States, not one such reallocation is provided for in the Draft. Quite to the opposite: European legislation would become easier in quite a few policy areas, which means that more laws and further centralization can be expected. The decision-rules used in order to provide public goods are a crucial component of every constitution. Unfortunately, the European Convention has not been able to propose precise modi according to which representatives of the Parliament, the Council, and the Commission are to be elected. But based on what the Convention did agree upon, what are the predictions one can make with regard to future activities of the Union? Will more or less legislative activity result? Will it lead to more or less centralization?

The rule of unanimity in the Council means that any member can prevent policies from being implemented. The rule of qualified majority voting (qmv), in turn, means that some $70 \%$ of the Council votes are sufficient to push a policy through. Increasing the importance of qmv can thus be expected to lead to more legislation being passed by the Council. The Draft Constitution proposes to reduce the areas for which unanimity is necessary from 84 to 37 . This means that there are 47 policy areas in which we can expect substantially more legislative activity on the European level.

The so-called "democratic deficit" of the European Union is often identified with the (low) number of areas in which the consent of the European Parliament (EP) is necessary in order to pass legislation. The Convention proposes to increase the use of the co-decision procedure in which the EP needs to agree from 37 to 92 . In order to pass fresh legislation, one does not only need the respective Council majority, but also a parliamentary majority. This means that it has become more difficult to pass fresh legislation, since two - instead of one - majorities are necessary. But the refraining effect of the EP concerning legislative activity on the European level seems to be more of an academic exercise than a real possibility: it is reasonable to assume that the median voter of the EP is more integrationist than the pivotal player of the Council. In all likelihood, the extended use of the co- 
decision procedure will therefore not prove to be a counterweight against the higher number of laws passed by the Council due to the change from unanimity to qmv.

The Convention has, however, proposed another institutional modification that might have some counterbalancing effect: it has strengthened the positions of the President of the Commission as well as that of the Council. The President of the Commission can, e.g., select his commissioners among three candidates nominated by the respective Member States. The strengthening of both positions can also be welcomed because they can be interpreted as a strengthening of the systems of checks and balances. ${ }^{1}$

To sum up: it has been argued that (i) too many public goods could be provided on the European level and that (ii) the decision-rules seem to favor a further centralization because the passing of additional legislation has been made cheaper by the Draft in many policy areas.

\section{Additional Issues}

We now turn to other rules that can, however, only be sketched very shortly.

- The Draft contains the possibility of exit from the Union. This can be interpreted as an ultimate veto right. Alluding to the possibility of using it can constrain a majority of other states to systematically neglect the interests of the member contemplating its use. Its effects should, however, not be overestimated: the threat of leaving will only remain credible if it is not used too often.

- The Draft contains the possibility of participatory democracy. At least one million citizens "may invite the Commission to submit any appropriate proposal on matters where citizens consider that a legal act of the Union is required for the Purpose of implementing this Constitution”. In general, direct democracy can serve as an additional check on government action and the possibility should thus be welcomed. Yet, the possibility is quite constrained and its effects should, again, not be overestimated: inviting the Commission to do something is, of course, not the same as having the right to make the Commission do something.

1 This is, however, only the case if two different persons are appointed to the two positions. The Draft does not exclude the possibility that one and the same person fulfills both functions which would be similar to having the President of one legislative chamber (the Council) be the head of the executive (the Commission). 
- The Draft establishes a new procedure that is to protect the principle of subsidiarity: a number of national parliaments can question whether the Union's actions are still in line with the principle. In case of non-agreement, the national parliaments can take the case to the ECJ. It is doubtful whether this constitutes an appropriate safeguard of the principle, given that the ECJ has been the most consistent player in extending the competence of the Union (Voigt 2003).

Observers have often noted that federal states seem to become ever more centralized and that the notion of subsidiarity does not have a constraining effect. What is thus needed is a mechanism against ever more centralization. The current architecture of the Union works in exactly the opposite direction: the acquis is considered as a minimum level of integration to be secured against any deviation. The German version of the Draft uses "Besitzstandswahrung” as the term which shows that currently, there is a ratchet-effect in favor of ever more integration. Due to the experiences with federal states, the exact opposite would be needed. One could, e.g., discuss the possibility of "sunset competence": a competence is allocated to the European Union level for a given number of years after which it automatically extinguishes if it is not prolonged unanimously by the Council.

\section{What to Do Now?}

The Draft Constitution has been criticized on various grounds. The question is how to improve it now? The length of the Constitution is stunning, its architectural complexity immense. In order to reach the aim of transparency, complexity needs to be reduced radically. Three approaches seem to suggest themselves:

- reduce the number of areas in which the Union has competence; tourism is just one example where competition between the Member States would lead to better products;

- the Charter of Fundamental Rights contains a number of positive rights that entail the danger of creeping further centralization, especially by the Court; it should be radically reduced to negative rights that are directly enforceable.

- A Constitution should contain the rules on how to provide public goods but not too many details on any public goods; there is a vast potential for shortening the Draft.

Ratification in all Member States is needed. The principal agent contract between the citizens of the Member States and their representatives at the Convention is a 
very imperfect contract. If the representatives to the Intergovernmental Conference know that the Constitution that they propose will be subject to a referendum at home, they have more incentives to take the preferences of the median voter at home into account. Member States should thus pass the necessity that referenda be used fast.

\section{References}

Buchanan, J. and Tullock, G. (1962); The Calculus of Consent - Logical Foundations of Constitutional Democracy, Ann Arbor: University of Michigan Press.

Voigt, S. (2003); Iudex Calculat - the ECJ's Quest for Power, to appear in: Jahrbuch für Nene Politische Ökonomie. 